ARTIGO

\title{
D. Quixote contra os moinhos: um ensaio sobre o Movimento Escola Sem Partido
}

\author{
Tiago Ribeiro Santos a \\ Gicele Maria Cervi ${ }^{b}$
}

\section{Resumo}

Este ensaio serve-se das categorias "sagrado" e "profano" com o objetivo de analisar ideias motoras do Movimento Escola sem Partido (MESP) que, como hipótese, procura instaurar uma visão de mundo escolar, apoiado em esquemas binários e convencionais de pensamento. Essas duas categorias procuram compreender como o MESP estabelece "deveres de condutas do professor" expressos em seu Projeto de Lei. Essa realidade político-educacional pode ser constituída de duas hipóteses: 1) pela construção social de um mundo heterônomo e virtualmente confuso e 2) pela atualização mítica de um tipo de professor "sagrado" que faria face ao mundo profano supostamente em questão. Estas sinalizam formas simbólicas de um passado cristalizado, constituindo aquilo que Bourdieu chamava de "paradigma de D. Quixote" - uma expressão subjetiva anacrônica à realidade objetiva. A realidade objetiva da educação é apresentada no último item do artigo, a partir de uma interpretação dramática onde tensões entre os valores "sagrado" e "profano" são entendidos como inerentes à condição social de professor.

Palavras-chave: Sagrado. Profano. Escola sem Partido. Moral.

\section{Introdução}

Não existe pior adversário científico, ao se trabalhar no e sobre o mundo social, que um adversário teoricamente frágil e socialmente forte (Pierre Bourdieu, 2015, p. 338).

A epígrafe acima, extraída do primeiro ano de cursos de Bourdieu no Collège de France, lembra que não é sem obstáculos sociais que os sociólogos realizam

\footnotetext{
a Universidade Regional de Blumenau, Blumenau, SC, Brasil.

b Universidade Regional de Blumenau, Blumenau, SC, Brasil. 
seu trabalho. Estes se veem, eventualmente, obrigados a analisar fenômenos aparentemente efêmeros que, todavia, não deixam de impressionar pela força com que se manifestam, e pela comoção pública que produzem. Os mais diversos projetos políticos, nesse sentido, quando procuram realizar-se por meio da escola, inevitavelmente levantam polêmicas, ao visarem a uma instituição concebida, mais ou menos heroicamente, como representante de valores, tais como liberdade, respeito e justiça social. A rigor, a comunidade escolar se agita, de modo que, por um lado, alguns tendem a reivindicar sua relativa autonomia contra todas as formas de opressão que poderiam ser investidas contra ela, enquanto que outros, mais confiantes nas promessas do Estado, reivindicam mudanças, embora seus resultados, dificilmente, possam ser mensurados. A análise de ideias, notadamente, políticos-escolares, logo, tende a tornar-se uma análise de disputas que se impõem em nome da escola, levando cientistas sociais a lidarem com um turbilhão de tomadas de posições oriundas dos mais diferentes grupos.

O ano de 2017, vejamos, registrou, na cidade de Campinas, São Paulo, a aprovação do Projeto de Lei Municipal (de ambição Federal), idealizado pelo Movimento Escola Sem Partido (MESP), que prevê a aplicação de cartazes nas salas de aula informando deveres acerca de "boas" práticas pedagógicas, notadamente destinadas aos professores. Essas "boas" práticas, como um manual de etiqueta do trabalho escolar, procuram prever uma relação pedagógica despojada de interesses políticopartidários, cujo professor, supostamente, poderia exercer sobre seus alunos, na forma de cooptação ideológica. O esforço do MESP volta-se, assim, à ação pedagógica do professor (CAPAVERDE; LESSA; LOPES, 2019), procurando imprimir uma legitimidade baseada na neutralidade do ensino. A polêmica em torno de professores, influenciados ou não, pelas esferas políticas, é, porém, bastante antiga, de modo que, em uma passagem de um conto de Machado de Assis, podemos observar sua presença nas práticas pedagógicas:

Não esqueçam que estávamos então no fim da Regência, e que era grande a agitação pública. Policarpo [o professor] tinha, decerto, algum partido, mas nunca pude averiguar esse ponto. $\mathrm{O}$ pior que ele podia ter, para nós, era a palmatória. E essa lá estava, pendurada do portal da janela, à direita, com os seus cinco olhos do diabo. Era só levantar a mão, despendurá-la e brandi-la, com a força do costume, que não era pouca. E daí, pode ser que alguma vez as paixões políticas dominassem nele a ponto de poupar-nos uma ou outra correção (ASSIS, 2007, p. 69).

As posições partidárias do professor Policarpo, supostamente, atuariam aí sobre suas decisões escolares, na forma de uma recusa pelo uso da palmatória, 
contrariando "a força do costume" da época. "No fim da Regência", ser "partidário" significaria, para o contista, portanto, um professor na contracorrente pedagógica de seu tempo, fazendo da escola um lugar menos sujeito às práticas violentas que hoje soariam como escandalosas. Este é, pois, um exemplo histórico de que "paixões políticas" e ações que representassem certas inovações do ponto de vista pedagógico estavam longe de se oporem uma à outra. O problema de ser "partidário" apenas parece, assim, sociologicamente plausível, quando contextualizado em um universo moral, e assim normativo, que prevê oposições entre práticas aceitáveis e reprováveis.

O jornal Folha de São de Paulo, por sua vez, procurou realizar, em março de 2017, uma mesa-redonda composta pelo idealizador do MESP, um professor aposentado de universidade pública e outros dois diretores de escolas privadas (SALDANHA, 2019). A mesa, exprimindo em sua própria configuração as polaridades extremas do mundo social, logo, degringolou em um jogo de acusações, cuja jornalista (ao meio mediando), em inúmeras vezes, foi obrigada a pedir silêncio ao público e moderação à mesa convidada. As relações, sobretudo entre antagonistas - lembra Bourdieu (2002) - devem contar, ao menos, com um ponto de acordo entre si para tornar possível um debate ${ }^{1}$. A ausência de pontos em comum tende a configurar, assim, fatalmente, uma forma de vulnerabilidade da imagem de professor e do discurso científico, uma vez que estão sujeitos à confusão dos "falatórios" das formas habituais e instintivas de pensamento.

Os assuntos polêmicos, afinal, estão cheios de ambiguidades, de modo que os cientistas sociais, embora correndo o risco de perderem a credibilidade, são chamados a atender às demandas jornalísticas, públicas, educacionais etc., oferecendo esclarecimentos e possíveis respostas. A emergência do MESP compõe essas polêmicas. As palavras de Weber parecem aqui a propósito, sobretudo, quando parece preciso se opor à "fraqueza" de "não ser capaz de encarar a face sisuda do destino do tempo em que se vive" (WEBER, 2013, p. 421). O mundo social está, evidentemente, repleto de pânicos morais, de modo que as ideias políticas parecem conter algo de diabólico. Weber (2013, p. 426), para isso, sugeria: "Pensem bem: o diabo está velho; então envelheçam para entendê-lo". O sociólogo alemão se referia ao "fato de que também desse diabo não se pode fugir caso se queira ver-se livre dele", assim como seria "preciso primeiro ter uma visão completa de seus caminhos para conhecer seu poder e seus limites".

As polaridades de certo jornalismo, como aquele que convida Pe. Quevedo e um paranormal para a gravação de um programa, induz falsamente ao debate à medida que coloca face a face dois indivíduos que tendem a se ignorar cotidianamente. Estas polaridades talvez retirem sua legitimidade da audiência produzida por um público de expectadores mais interessado em assistir a um desentendimento extremo que confiante na possibilidade real de ouvir argumentações, de ambos os lados, plausíveis. 
Esses mesmos limites, ora, por que não definem a realidade de grupos de indivíduos aderentes à ideia de que o cartaz do MESP deve (ou não) ser posta em prática? A formulação de um problema sociológico fundamental, por vezes, "consiste menos em determinar por que algumas coisas 'saem erradas' do ponto de vista das autoridades do que conhecer como todo o sistema funciona, quais são os seus pressupostos e como ele se mantém coeso" (BERGER, 1980, p. 47). Essa coesão, condição de plausibilidade de um projeto político aos moldes do MESP, é que serve de análise. $\mathrm{O}$ mesmo seria dizer que, se para uns, esse projeto se apresenta como anacrônico ou autoritário, para outros, ele representa uma narrativa apoiada, inclusive, em certo patrimônio sociológico, como o de Max Weber, referenciado na página do MESP (ESCOLA SEM PARTIDO, 2004a), com a seguinte citação:

Em uma sala de aula, a palavra é do professor, e os estudantes estão condenados ao silêncio. Impõem as circunstâncias que os alunos sejam obrigados a seguir os cursos de um professor, tendo em vista a futura carreira; e que ninguém dos presentes a uma sala de aula possa criticar o mestre. É imperdoável a um professor valer-se dessa situação para buscar incutir em seus discípulos as suas próprias concepções políticas, em vez de lhes ser útil, como é de seu dever, através da transmissão de conhecimento e de experiência científica.

O trecho em questão, enfatizando uma ideia racional e útil de professor, possivelmente poderia ser relativizado, deixando ver melhor seus próprios limites, à medida que Weber antevia uma "jaula de ferro" como resultado da escalada do pensamento instrumental no Ocidente - como nas últimas e nostálgicas páginas de A ética protestante. O que convém, entretanto, não se trata de explorar a vulnerabilidade de uma ideia fora de lugar, tal como o enxerto de Weber no projeto acima, mas, de tratar as "dicotomias simplistas [do MESP], que reduzem questões complexas a falsas alternativas" (PENNA, 2017, p. 35) na forma de severas divisões de história bastante antiga. O que importa saber é, pois, como essa ideia se modela e se mantém operante em um universo simbólico que se impõe como crível, fundamental e necessário, deixando passar despercebido seu caráter predominantemente ideológico, ou seja, nos termos do próprio Weber (2013), sua visão relativa de mundo.

A análise aqui apresentada pode se voltar, assim, ao caráter funcional do MESP, cuja força parece provir de elementos sui generis que, por um lado, podem ser considerados socialmente anacrônicos e, por outro, sociologicamente sincrônicos. Esse seria o caso da exploração da relação entre o "sagrado" e o "profano" que ocupou um lugar significativo nas ciências sociais desde o final do século XIX 
(NISBET, 1984). A análise de ideias filiadas principalmente a elementos "sagrados" talvez torne compreensível, assim, não apenas a direção do MESP, mas, também seus pontos de chegada já sinalizados em Frigotto (2017). Esse seria o caso de distopias sobre uma escola que procura passar a imagem de "santificada" e "inimiga" de seus contrários; de práticas pedagógicas pautadas na satisfação de necessidades tópicas e que, por força de seu discurso, eclipsam a própria "liberdade de aprender, ensinar, pesquisar e divulgar a cultura, o pensamento, a arte e o saber" (BRASIL, 2018, p. 9), legalmente prevista.

\section{Uma perspectiva metodológica: sobre o cartaz de "Deveres do Professor"}

A análise de uma lista de deveres do trabalho escolar não deve perder de vista que a escola moderna, como um instrumento de políticas de Estado, dispõe-se a ser uma instituição autorizada a agir através desse mesmo Estado. Na forma de projetos de lei, o Estado tem a possibilidade particular de enunciar prováveis mudanças sobre o mundo social, de modo que, "enquanto enunciado performativo, a 'pré-visão' política é, por si só, uma 'pré-dição', que pretende fazer acontecer o que enuncia; ela contribui praticamente para a realidade do que enuncia, pelo fato de enunciá-lo" (BOURDIEU, 1996, p. 118). Nas enunciações políticas sobre o mundo escolar, em termos de direitos e deveres, encontra-se um dos efeitos talvez mais concretos de sua força: a de produzir, a partir do MESP como grupo, divisões internas sobre outros grupos - de diretores, pais, estudantes e professores, por força do próprio discurso de oposição que esse movimento reivindica.

As ações políticas são, assim, objetos de conhecimento público, ou seja, objetos dispostos a serem percebidos e apreciados pelo público na forma de juízos que podem veicular, no mais das vezes, indignações da parte de todos aqueles que têm algo a perder ou a ganhar com essas ações. No caso do MESP convém, portanto, assumir, inicialmente, que o discurso reivindicado pelo movimento, que se define como neutro, racional e justo, procura imprimir inevitavelmente um curso às ações educacionais, e cujo cartaz de "Deveres do Professor" serve como recurso. Esse recurso, como um meio simbolizador das divisões ou das oposições, tem ainda a função de exprimir "a transição do estado de grupo prático ao estado de grupo [que se quer] instituído” (BOURDIEU, 1996, p. 120), discursando sobre atributos ideais do papel de professor. A figura abaixo apresenta esses atributos que, talvez, teriam todas as chances de aderir a uma doxa (opinião) dominante que vê uma sociedade em estado de, ao menos, decadência moral. 


\section{Deveres do professor}

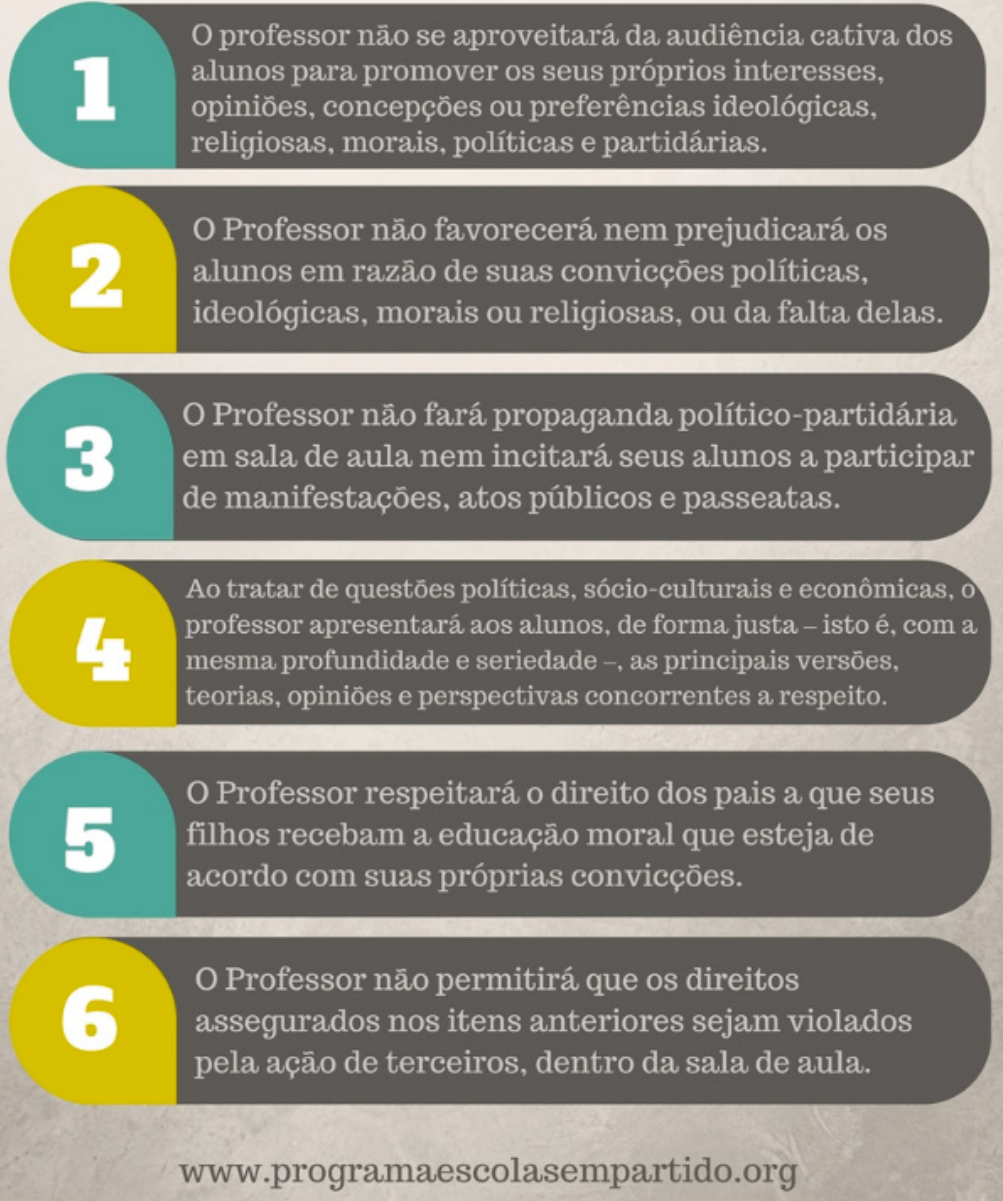

Fonte: https://www.programaescolasempartido.org/ (ESCOLA SEM PARTIDO, 2004a).

Figura. Cartaz difundido pelo Movimento Escola Sem Partido.

Esses deveres, a rigor, são meios discursivos dispostos a produzirem certo consenso sobre o mundo educacional. Na etimologia do termo discurso, todavia, reside, um prefixo de negação que faz do (dis)curso, igualmente, um (ex)curso: uma forma de desvio em direção ao poder do Estado que, por sua vez, enuncia um novo curso à ordem social de sua população através de recursos oficialmente 
instituídos. A enunciação de um discurso que é, portanto, negação de um curso, rumo ou caminho, dificilmente, pode ser exercido sem a ambiguidade de nomear também seu contrário, ainda que tacitamente. No campo dos contrários, encontrase justamente a reivindicação da "sala de aula" como uma sala "de curso" e, portanto, não "de discursos", fazendo dela um alvo das investidas do MESP contra os possíveis discursos partidários de professores. O discurso do MESP necessita, assim, de um (re)curso: um meio (como o cartaz) que dê outro curso às relações educacionais, em defesa de uma realidade, aparentemente, fora de rumo, em declínio. Esse discurso, entretanto, ao procurar penetrar no curso da sala de aula, atuando sobre seus conteúdos, incorre na abstração de descrever uma realidade que ele mesmo prescreve, autoafirmando-se assim como uma forma ideológica de política pedagógica.

Nas descrições e prescrições do MESP, que tem de encarar as próprias oposições que ele demarca, prevê-se aqui a análise de duas estratégias discursivas, entre as quais estão: 1) a fundação de um ponto fixo, uma orientação, em resistência ao suposto estado (profano) de caos e de vulnerabilidade em que se encontra o mundo escolar; e 2) a atualização de um professor abstrato cujas condutas devem estar à altura da imagem (sagrada) de escola que o MESP tenta produzir para conservar. O mesmo seria dizer que o MESP somente pode se autoafirmar ao criar (e desclassificar) seu próprio inimigo, inventando um projeto heroico de combate às mazelas educacionais - como $\mathrm{D}$. Quixote que necessitava de suas próprias ilusões para combater gigantes, quando, em verdade, tratavam-se apenas de moinhos.

\section{Heteronomia e fundação de um ponto fixo}

Examinado de maneira estrutural, o MESP provavelmente reúne atributos comuns a esquemas sociais que sustentam valores, normas e crenças. Estes atributos, inicialmente, parecem girar em torno de uma separação essencial, que prevê, nos termos de Eliade (1992, p. 17), por um lado, o espaço "sagrado" como um "Centro" que define um ponto fixo, de referência, e, por outro, o "caos" da homogeneidade e da relatividade do espaço profano. Esta separação, frequente no universo da moral, notadamente, reflete um jogo de oposições, exprimindo visões de mundo que orientam posicionamentos individuais, classificações, julgamentos etc. O mundo, aí, tende a ser repartido em, ao menos, duas partes, de modo que o que jaz em seu meio pode servir ao escrutínio científico. A análise de uma estrutura que produz polaridades seria, pois, uma forma de encontrar um meio que opera em nome de sua conservação, sem desconsiderar seus próprios conflitos ${ }^{2}$.

A obra pedagógica de Durkheim pode ser observada como exemplo de um pensamento estrutural que incorpora, ao mesmo tempo, a ordem e o conflito (CHERKAOUI, 1976). O papel que o sociólogo confere à "Educação Moral" 
O cartaz de "Deveres do Professor" apresenta, inicialmente, seis obrigações que, por sua vez, podem ser categorizadas em duas ordens: uma, compreendendo os deveres $\mathrm{n}^{\circ} 1,2,3$, que prevê um professor heterônomo e, assim, disposto a agir sem obedecer a valores considerados inalienáveis na Educação; e outra, expressa nos deveres $\mathrm{n}^{\mathrm{o}}$ 4, 5 e 6, prevendo um professor autônomo, logo, fazendo justa oposição às formas virtualmente recrimináveis de ensino. No meio da balança, entre um peso e outro, encontrar-se-ia a própria personalidade de um professor inicialmente sem qualidades e, por isso, pré-disposto tanto às tentações pessoais e profanas de reivindicar uma personalidade partidária quanto às obrigações sociais e sagradas de exercer seu papel de acordo com limites firmados por escrito (e, por isso, convencionalmente definidos).

A visão de um mundo sem rédeas, nesse sentido, de impulsos pessoais, ora, por que não seria a mesma que prevê um professor que não deve se aproveitar "da audiência cativa dos alunos para promover os seus próprios interesses, opiniões, concepções ou preferências ideológicas, religiosas, morais, políticas e partidárias", conforme dever $\mathrm{n}^{\circ} 1$ ? Os comportamentos, aí antecipados, poderiam compor um index de impropriedades que, do ponto de vista normativo, significariam negligências da conduta do professor, sujeitando-o à correção. Essa previsão de negligência, ao fazer crer que a responsabilidade pela qualidade da educação reside mais no professor e menos em órgãos institucionais, com efeito, transfere para a esfera das ações pessoais os interesses de atuação políticos-pedagógicos.

$\mathrm{Na}$ forma de uma pré-visão da conduta de professor, Weber (2013, p. 417) fazia críticas semelhantes quando, em um "auditório, onde o sujeito fica sentado diante de seus ouvintes", um professor tem a "irresponsabilidade de se aproveitar dessa circunstância, de que os estudantes, para poderem avançar em seus estudos, precisem frequentar o curso", não havendo "ninguém presente que lhe oponha crítica" e, assim, marcando, mais facilmente, seus alunos com "sua visão política pessoal". Essas impropriedades, logo, servindo de chamados à ordem, indicam os valores morais que pesam sobre o papel de professor e que o definem, notadamente, não pelas suas competências e inteligências, mas, pelos seus comportamentos. Essa virada do ponto de interesse, representado pela definição de um ponto fixo, com efeito, nivela a educação por baixo, suspeitando da autonomia do professor para, assim, fazer crer na existência de um Estado potente disposto a se ocupar dela:

é, pois, uma forma de conceber uma força integradora que age sobre os indivíduos, orientando suas condutas sociais e produzindo autonomia em uma sociedade de forte diferenciação social e moderna. 
[...] o esforço em aprovar o Projeto de Lei Escola sem Partido, para limpar as escolas de qualquer ideologia, proibindo que o professor assuma diante de seus alunos suas posições políticas e religiosas, no fundo visa retirar do docente seu caráter exemplar, daquele que sabe pensar, isto é, colocar-se apropriada e pessoalmente diante de novas situações (GIANNOTTI, 2019, p. 137).

A extensão do repertório de deveres professorais, porém, parece algo também fluido, indefinido, negociável e não limitado pelas paredes da sala de aula, de modo que, dificilmente, se pode dizer onde começaria e onde terminaria uma relação pedagógica. Essa marca de imprecisão das relações é que, por sua vez, pode inspirar tentativas de precisão: como no caso do Projeto de Lei brasileira $\mathrm{n}^{\circ} 955$ (BRASIL, 2015), que vetava "aos membros do Ministério Público e da Magistratura Nacional a publicação de conteúdo na Internet", declarando que, "apesar de todos os benefícios alcançados, as redes sociais também podem trazer prejuízos para a vida das pessoas e para a organização política e social de comunidades e até mesmo do país" (BRASIL, 2015). Esse projeto se dirigia aí, principalmente, sobre "autoridades que, por dever do ofício, devem posicionar neutralidade em questões conflitantes" - questões, então, que a comunicação via Internet tenderia a embaralhar ao mediar relações entre essas autoridades e seus públicos. A heteronomia, a qual estaria sujeita o papel do professor, se regula, assim, através de um recuo das formas de comunicação. O professor passaria a estar protegido da circulação caótica de conteúdos na internet, de modo que seu valor sagrado permaneceria no fato de não ser tocado pelas contingências do mundo moderno.

A definição, portanto, de uma linha, uma marca separadora, parece permanecer no coração das definições oficiais do ofício pedagógico ${ }^{3}$. A vida social tem, entretanto, suas próprias maleabilidades, de modo que um professor, na Internet, poderia se servir de um avatar ou de nickname a fim de manter contato com seus alunos, despistando meios oficiais e legais de definição da situação escolar, contornando essa linha divisória. Essa mesma linha, representada, seja pelo dever $\mathrm{n}^{\mathrm{o}} 1$ do MESP ou pelo Projeto de Lei sobre a Internet, ora, por que não significaria uma delimitação - por outros, visto como uma "aprimoração" - da imagem do professor? A sua representação, permanecendo afastada de algo profano, passa a supor a existência de uma zona restrita, privada, exterior e, tão logo, inacessível

\footnotetext{
A Educação, interpretada como uma história das separações, provavelmente estimularia pesquisas dispostas a mostrar que a regulamentação da atividade pedagógica tende a se subordinar às relações de proximidade e distância entre professores e alunos. Moulin (1994, p. 386) lembra que, na Idade Média, "os contatos dos alunos com o Mestre, que os chamava de seus 'familiares' ou 'da família', porque alguns habitavam na mesma casa do professor, que recebia hóspedes, eram íntimos e diretos. Viviam sob o mesmo teto, iam juntos aos ofícios ou à taberna".
} 
a um público. $\mathrm{O}$ mesmo seria dizer que existe algo que deve se manter escondido ou protegido em recintos notadamente mais secretos, que servem de manutenção a uma imagem, ao mesmo tempo, profissional e pessoal.

A atividade dos professores, sujeita, então, a um ponto fixo, e, ao supor aspectos virtualmente conflituosos, justifica, assim, a construção de uma espécie de linha divisória, prevendo um professor definido por meio de "que nãos": "que não favorecerá nem prejudicará os alunos" $\left(\right.$ dever $\left.\mathrm{n}^{\circ} 2\right)$, e "que não fará propaganda político-partidária em sala de aula" (dever $\left.\mathrm{n}^{\circ} 3\right)$. O que pode haver no mundo, em matéria de "profano", de "impossível", como algo que vem de "fora", tende a se tornar, assim, um oponente do MESP, uma vez que seu artifício argumentativo consiste em separar a realidade da Educação em duas. O apelo aos conteúdos virtuais, fotos, flagrantes de professores partidariamente engajados etc., descontextualizados ou não, visíveis no site do MESP, logo, tenderia a contribuir a essa construção da realidade baseada em ditos e não ditos, baseada, portanto, em uma imagem de professor performaticamente construída. Essa é, pois, uma forma sociológica não apenas clássica de definição da realidade, mas, também, comunitária, onde geralmente a prática da "fofoca", forma rudimentar de controle social, mostra-se suficientemente eficaz para construir uma imagem depreciativa do outro (ELIAS; SCOTSON, 2000).

Essa separação abstrata entre professores de "dentro" e de "fora" pode ser estendida, respectivamente, a um esquema que censura aspectos difusos da Educação, ou seja, sua heteronomia em matéria de métodos e conteúdos. O caso de Sócrates é exemplar, no sentido de que a difusão de sua Educação era também difusa no sentido de compor elementos que colocavam em questão o regime político de sua época, IV a.C. A suposta incompatibilidade entre a difusão da Educação e seu caráter difuso conduz, com efeito, à tentadora lógica de eliminação desse último. Os valores sagrados aí apenas se conservam sob a prática do "sacrifício", de modo que a perseguição a Sócrates pode ser sempre reatualizada por meio da forma que veremos a seguir.

\section{Sacrifício e atualização de um mito}

Os mitos têm a função de contar "uma história sagrada, quer dizer, um acontecimento primordial que teve lugar no começo do Tempo" (ELIADE, 1992, p. 49). A formação de uma realidade primordial, em termos míticos, esteve, até aqui, subordinada a uma separação essencial que constrói, com efeito, um mundo profano, impossível. Essa operação simbólica é que permite prosseguir na análise, compondo uma representação razoavelmente fabular do professor, então, purificada de aspectos profanos, que supostamente fariam parte do mundo 
escolar. Nas palavras de Lemos (2019), para vencer disputas política, hoje, seria preciso dispor de uma "narrativa política" capaz de criar personagens, e, principalmente, criar inimigos bons para serem odiados e combatidos, entre os quais se encontraria, aqui, a famigerada imagem do professor-doutrinador.

Esta narrativa é que condiciona a invenção de um sagrado, como uma realidade moral que se atualiza - e assim se faz presente frente ao seu próprio passado através de ritos que inspiram sentimentos de comunhão coletiva, solidariedade etc. A atualização intermediada pelo rito, com efeito, ritualísticamente, celebra o sagrado ao mesmo tempo que isola o profano. O nome sugestivo de "lei da mordaça", atribuído ao "Escola Sem partido" é, pois, uma expressão tanto desse isolamento que seu rito produz, quanto da representação de uma prática pré-moderna a fim de impedir possíveis "heresias".

O que importa, ainda, é que essas "heresias" tenham a impressão de terem sido denunciadas pelo próprio povo (LEMOS, 2019) e que, portanto, quanto mais popularmente censuradas, mais tendam a nutrir reações populistas. Essas reações, facilitadas por uma aparelhagem de delação, como expressa na página do MESP na Internet, procuram definir as formas de identificação de um processo de doutrinação, flagrando um professor que: "impõe a leitura de textos que mostram apenas um dos lados de questões controvertidas"; "pressiona os alunos a expressarem determinados pontos de vista em seus trabalho"; ou "omite ou minimiza fatos desabonadores à corrente político-ideológica de sua preferência" (ESCOLA SEM PARTIDO, 2004b).

Essas "heresias" poderiam, afinal, provir de um professor partidariamente vocacionado, conforme dever $\mathrm{n}^{0} 3$, previsto pelo Projeto de Lei: “o professor não fará propaganda político-partidária em sala de aula nem incitará seus alunos a participarem de manifestações, atos públicos e passeatas". O Mestre, em sala, se confunde, virtualmente, a uma entidade perigosa, ou seja, com uma projeção quixotesca de quem ergue sua espada contra moinhos de vento, julgando tratarem-se de gigantes. D. Quixote expressa, pois, uma visão deslocada da realidade objetiva do mundo; aquilo que Bourdieu (2015, p. 381) chamava de um caso paradigmático na forma de uma visível incompatibilidade entre suas "disposições subjetivas e a objetividade do mundo social”. A visão de D. Quixote se trata, assim, de uma projeção individualizada, e, portanto, dividida da realidade, recusando a coexistência de contradições e paradoxos na vida em sociedade.

A relação entre D. Quixote e Sancho Pança, com acréscimo, expressa justamente essa contradição à medida que este último, seu escudeiro, procura atualizar 
D. Quixote a fim de convencê-lo do engano de estar frente a um inimigo em potencial:

— Que gigantes? - disse Sancho Pança.

— Aqueles ali, de braços compridos — respondeu o amo. — Alguns costumam ter braços de quase duas léguas.

— Olhe Vossa Mercê — respondeu Sancho —, aqueles que estão ali não são gigantes, mas moinhos de vento, e o que neles parecem braços são as pás, que, rodadas pelo vento, fazem trabalhar as mós.

- Bem se vê - respondeu Dom Quixote - que não és versado em aventuras: eles são gigantes. E, se tens medo, some-te daqui e fica rezando enquanto isso, porque vou travar com eles uma batalha feroz e desigual (CERVANTES, 2012 p. 65).

A luta do MESP, através de D. Quixote, representada como repetição de uma narrativa social, ignorando formas comuns de atualização da construção da realidade - ciência, arte, jornalismo - tão logo deve lançar mão de outros arsenais de atualização. Estes, tão heterogêneos quanto espalhados pelo mundo social, e geralmente melhor representados pelas associações de redes sociais on-line, vídeos na internet, artigos curtos, trechos de Max Weber etc., por sua vez, servem à construção da imagem de professores politicamente vocacionados, como se simbolizassem os gigantes que impedem D. Quixote de levar a cabo seu destino. O papel do escudeiro Pança, talvez, apenas se justifique pelo fato de que a conservação de uma visão mítica da realidade é essencial à continuidade da aventura de D. Quixote vivida, então, menos sobre o real e mais sobre o virtual: sobre um hipotético ser que, ao projetar uma situação, está forçado a conter meios próprios de atualização da realidade, podendo chegar à teimosia e insistindo sobre a existência de professores partidários atuando contra um ideal escolar.

Essa construção imaginária da relação escolar, com efeito, ao inventar a imagem de um professor profano, atua em nome de fazer desaparecer o caráter intelectual, difuso, que compõe uma milenar autoridade do professor. A cidade de Paris, seguramente, não seria a capital do ensino na Europa do século XII sem Abelardo, teólogo e filósofo, recebido na cidade de Soissons, em 1121, "à base de pedradas oriundas de uma multidão indignada", acusando o Mestre teólogo de herege (PERNOUD, 1977, p. 112). A distopia do MESP guarda aí algo de astuto porque, munida de suposta neutralidade científica e política, pode alegar estar protegendo os próprios professores contra as injúrias que, um dia, pesaram sobre outros professores como Abelardo. 


\section{O drama do professor: profanar para educar}

O MESP sacrifica professores em nome do valor sagrado de sua distopia. Essa poderia ser uma síntese do drama aqui analisado, uma vez que faria sair de cena um professor julgado heterônomo. $\mathrm{O}$ que convém agora, face a um conceito ideal de professor, não se trata de encontrar uma correspondência na realidade, mas, de atribuir ao MESP uma identidade conceitual. Essa identidade remonta, mais precisamente, a um problema clássico referente aos usos políticos das ideias científicas, representados pela obra $A$ traição dos clérigos de Benda (1975). A tese do autor marca a história dos intelectuais no contexto europeu dos anos 1930, podendo ser resumida da maneira seguinte: "os homens, cuja função está em defender os valores eternos e desinteressados, como a justiça e a razão", que poderiam ser chamados de intelectuais, "traíram essa função se beneficiando de interesses práticos” (BENDA, 1975, p. 49).

A traição, aqui representada pelas ideias políticas que se nutrem, mais ou menos, da ciência, está para muito além do trabalho de enxertar trechos de Max Weber a fim de se equipar com conteúdos que produzam um efeito de crença coletiva. A traição está, mais precisamente, em conferir ao profano da Educação aspectos contraprodutivos, incômodos, impossíveis. Os professores e filósofos na Antiguidade, ou Mestres na Idade-Média, afinal, sempre foram constituídos de uma tensão essencial: a de exceder limites que colocam suas próprias integridades em risco. Sócrates não teria sido o primeiro a expressar essa tensão ao divergir dos ideais da pólis e corromper a juventude grega, segundo acusações que resultaram em sua pena de morte. Sócrates, mais tarde consagrado "pai da filosofia ocidental", e sua máxima "só sei que nada sei", ainda ecoa - de maneira, porém, mais prolixa - na visão de Pascal sobre a relação do homem e das Ciências:

As ciências têm duas extremidades que se tocam: a primeira é a ignorância natural de todos os homens que veem ao mundo; a outra é aquela aonde chegam as grandes almas que, tendo percorrido tudo o que os homens podem saber, veem que eles nada sabem em comparação ao que tem de aprender, reencontrando-se na mesma ignorância da qual haviam partido. Essa, contudo, se trata de uma ignorância sábia, esclarecida, que se conhece (PASCAL, 1962, p. 58).

Essas "duas extremidades" podem, por sua vez, ser antropologicamente interpretadas como expressão do "dualismo da natureza humana" (DURKHEIM, 2013), onde uma parte "sagrada" e outra "profana" seriam constitutivas do indivíduo. Durkheim sinalizava uma forma dramática da condição humana que em contrapartida - estimularia o desenvolvimento da cultura ao requerer esforços 
coletivos em nome de constantes tentativas de remediação. Eliade (1992) se somaria a esta compreensão, ao tomar a "dessacralização" como uma força motora da modernidade. A imagem, porém, de um indivíduo completamente dessacralizado - profano, então, até a última gota - seria um absurdo do ponto de vista empírico. O sagrado significa, antes, a fundação de um ponto fixo que, traduzido em termos seculares, poderia bem ser representado pelo "cotidiano" como a "realidade par excellence" (BERGER, LUCKMAN, 1967 , p. 21) que orienta mulheres e homens em seus mundos. O que importa é que o "profano" permanece no mundo através de elementos simbólicos que cercam este ponto fixo.

A natureza tensa entre o sagrado e o profano faria, enfim, parte da vida social. Essa tensão pode ser observada na obra "A evolução pedagógica", na qual Durkheim (1938) observara desde cedo algo de profano na embrionária tarefa católica de educar o Ocidente. O ensino de Deus ocorria, também através do ensino da leitura, permitindo aos povos pagãos o acesso à divina Escritura. Um risco, todavia, seria iminente à medida que os jovens noviços pudessem vir a amar mais as letras que a Deus; ou mais a gramática que o texto sagrado. A história do ensino - e dos indivíduos responsáveis em ensinar - ganha, enfim, aspectos dramáticos quando a transmissão de uma educação pode perturbar seus próprios objetivos ${ }^{4}$.

A educação tenderia, assim, a consistir em uma relação em que o sagrado e o profano permanecem em conflito. A obra de Durkheim, nesse sentido, não deixou de sublinhar o papel de Abelardo (1079-1142) que, embora expulso da cidade de Laon, por força de ter ensinado sem o título de "Mestre" (DURKHEIM, 1938, p. 103), marcara a história da educação como um pensador, ao mesmo tempo, inovador e profano para sua época. Esse exemplo histórico chama atenção ao fato de que o papel de professor parece tão mais dramático quanto mais sujeito a injunções externas manifestadas por obrigações, códigos e protocolos, pelos quais ele é autorizado a exercer a relação pedagógica.

O sentido dramático da vida social não se encerra, entretanto, no aspecto agônico do termo. A sociedade, como um drama, pode ser entendida como uma representação coletiva de indivíduos (atores) atuando através de papéis sociais (personagens), ao longo da vida cotidiana. A sociedade é assim: um drama, porque ela funciona como se fosse também um teatro. Erving Goffman é, possivelmente, o autor que, mais exaustivamente, procurou extrair as consequências empíricas e teóricas de uma perspectiva dramatúrgica aplicada à vida social, privilegiando o cotidiano

\footnotetext{
4 A palavra transmissão pertence ao mesmo grupo etimológico que reúne os termos tradição e traição: por isso um ato de transmissão pode servir tanto a perpetuação de um costume quanto à difusão indevida de um segredo.
} 
como um espaço de realidades compartilhadas; onde inclusive, indivíduos que se opõem em matéria de ideais e interesses estariam dispostos a encontrarem-se e a conservarem formas de interação.

Os estudos em Educação, logo, podem problematizar a condição de professores cujos interesses não se realizam, necessariamente, na estrutura da sociedade em que se encontram; ou que se realizam em mundos compartilhados entre pares tão mais restritos quanto mais semelhantes a eles mesmos. Essa tensão poderia ser traduzida em questões contemporâneas que variam desde as interações com seus alunos em espaços na Internet até ao direito à manifestação política. Os contextos urbanos, afinal, fermentam ideias, conflitos, revoluções, contrarrevoluções, que fazem da modernidade uma aventura sem direção prévia, aberta ao inesperado, ao contingente, às virtualidades. $\mathrm{O}$ medo à virtualidade permanece, entretanto, presente, de modo que indivíduos que "deixam de agir e passam a comportarem-se de acordo com a normatividade" (GUILHERME, PICOLI, 2018) aprazem como uma realidade imaginada pelo MESP, que pelos seus próprios medos faz do seu cartaz um meio de dominação.

\section{Post-scriptum}

A construção de uma ideia política vinculada às tensões entre "sagrado" e "profano" na Educação deve permitir observar, enfim, que no coração dos próprios processos educacionais residem conflitos sem fim. As reivindicações do MESP, entretanto, dificilmente representariam profanações do ponto de vista educacional: porque suas reclamações permanecem mais preocupadas em dar forma ao que já seria próprio da religio (AGAMBEN, 2007, p. 66): não ao "que une homens e deuses, mas aquilo que cuida para que se mantenham distintos". A distinção, nesse sentido, supõe uma forma de desvalorização, posto que apenas podem ser consideradas "distintas" coisas que têm entre si valores desiguais, constituindo uma estrutura de opostos - justo/arbitrário, moral/vergonhoso, seriedade/enganação.

As exigências do MESP podem ser lidas, assim, como um esforço preocupado em estabelecer separações e oposições, encontradas também em outras esferas das políticas educacionais. Macedo (2017), nesse sentido, pôde observar na atuação do MESP, frente às negociações de preparação da Base Nacional Curricular Comum (BNCC), uma produção de novas divisões, por exemplo, "em prol da separação entre espaço público e privado, transferindo a Educação para o espaço privado da família, a quem caberia toda a formação moral e ética das crianças" (Macedo, 2017, p. 515). A Educação, aí, se reatualiza como narrativa que, contemplando divisões de mundos, contribui à (re)construção do sagrado e, com 
efeito, às tentações de pensamentos que retrocedem na forma de uma educação que restringe a autonomia docente.

Essas considerações, ainda, talvez não sejam suficientes para resumir que o MESP se serve de antigos modelos estruturais para construir um espaço profano de atuação docente. Esse mesmo espaço, funcionando como um opositor e não como um cooperador da Educação, logo, coloca em descrédito as margens de autonomia docente. A Escola Sem Partido, como uma escola sem profanação, seria igualmente mais cinza e sem vida, produzindo formas particulares de higienização, medos, isolamentos. A literatura de Orwel, Huxley, Burgess etc. sobre mundos imaginados traz inúmeros exemplos sobre esses processos - e por isso não seria estranho que educadores (THIESEN; BIANCHETTI, 2014) tenham se reunido em torno de utopias e distopias que portam, tanto umas quanto outras, verdadeiros problemas educacionais. 


\section{Quixote against the mills: an essay on the Movimento Escola sem Partido in Brazil}

\section{Abstract}

This essay debates the ideas of the Movimento Escola Sem Partido (MESP) by the "sacred" and "profane" categories analyses. These categories seek to understand how MESP establishes "duties of teacher's conduct" expressed in its Bill. This politicaleducational reality can be constituted of two hypothesis 1) by the social construction of a heteronomous world and virtually confusing, and (2) by the mythical actualization of a kind of "sacred" teacher who would face the supposed profane world. These hypotheses signal symbolic forms of a crystallized past, constituting what Bourdieu called the "Quixote paradigm" - an anachronistic subjective expression of objective reality. The objective reality of education is presented in the last section of the article from a dramatic interpretation where tensions between "sacred" and "profane" values are understood as inherent in their social condition.

Keywords: Sacred. Profane. School without Party. Moral.

\section{Quijote contra los molinos: un ensayo sobre el Movimiento Escuela sin Partido en Brasil}

\section{Resumen}

Este ensayo se sirve de las categorías "sagrado" y "profano" con el objetivo de analizar ideas motoras del Movimiento Escuela sin Partido (MESP) que, como hipótesis, buscan instaurar una visión de mundo escolar, apoyado en esquemas binarios y convencionales de pensamiento. Estas dos categorías buscan comprender cómo el MESP establece “deberes de conductas del profesor" expresados en su Proyecto de Ley. Esta realidad político-educativa puede ser constituida de dos hipótesis: 1) por la construcción social de un mundo heterónomo y virtualmente confuso y 2) por la actualización mítica de un tipo de profesor "sagrado" que haría frente al mundo profano supuestamente en cuestión. Estas hipótesis señalan formas simbólicas de un pasado cristalizado, constituyendo eso que Bourdieu llamaba "paradigma de don Quijote" - una expresión subjetiva anacrónica a la realidad objetiva. La realidad objetiva de la educación es presentada en el último item del artículo a partir de una interpretación dramática donde tensiones entre los valores "sagrado" y el "profano" son entendidos como inherentes a su condición social de profesor.

Palabras clave: Sagrado. Profano. Escuela sin Partido. Moral. 


\section{Referências}

AGAMBEN, G. Profanações. São Paulo, SP: Boitempo, 2007.

ASSIS. M. Conto de escola. In: SANCHES NETO, M. (Org.). Contos para ler na escola. Rio de Janeiro, RJ: Record, 2007. p. 65-78.

BENDA, J. La trahison des clercs. Paris: Bernard Grasset, 1975.

BERGER, P. Perspectivas sociológicas: uma visão humanística. 5. ed. Petrópolis, RJ: Vozes, 1980.

BERGER, P.; LUCKMANN, T. The social construction of reality: a treatise in the sociology of knowledge. New York, NY: Archor, 1967.

BOURDIEU, P. Descrever e prescrever: as condições de possibilidade e os limites da eficácia política. In: BOURDIEU, P. A economia das trocas linguísticas: o que falar quer dizer. São Paulo, SP: Universidade de São Paulo, 1996. p. 117-27.

. Questions de sociologie. Paris: Minuit, 2002.

. Sociologie génerale: cours au collège de France 1981-1983. Paris: Raisons d'Agir, 2015.

BRASIL. Projeto de lei complementar 995/2015, de 26 de março de 2015. Acrescenta dispositivo à Lei $\mathrm{n}^{\circ} 12.965$, de 23 de abril de 2014, que estabelece princípios, garantias, direitos e deveres para o uso da internet no Brasil. Diário Oficial da União, 27 mar. 2015.

BRASIL. Senado Federal. Lei de diretrizes e bases da educação nacional. 2. ed. Brasília, DF, 2018.

CAPAVERDE, C. B.; LESSA, B. S.; LOPES, F. D. "Escola sem partido" para quem? Ensaio: Avaliação e Políticas Públicas em Educação, Rio de Janeiro, v. 27, n. 102, p. 204-22, mar. 2019. https://doi.org/10.1590/s0104-40362018002601369

CHERKAOUI, M. Socialisation et conflit: les systèmes éducatifs et leur histoire selon Durkheim. Revue Française de Sociologie, Paris, v. 17, n. 2 , p. 197-212, 1976.

CERVANTES, M. Dom Quixote. São Paulo, SP: Penguim, 2012.

DURKHEIM, E. L'évolution pédagogique en France: des origines a la renaissance. Paris: Librarie Félix Alcan, 1938. 
DURKHEIM, E. O dualismo da natureza humana e suas condições sociais. In: BOTELHO, A. (Org.). Essencial sociologia. São Paulo, SP: Companhia das letras, 2013. p. 291-307.

ELIADE, M. O sagrado e o profano: a essência das religiões. São Paulo, SP: Martins Fontes, 1992.

ELIAS, N.; SCOTSON, J. Os estabelecidos os outsiders: sociologia das relações de poder a partir de uma pequena comunidade. Rio de Janeiro, RJ: Zahar, 2000.

ESCOLA SEM PARTIDO. Por uma lei contra o abuso da liberdade de ensinar. São Paulo, SP, 2004a. Disponível em: $<$ https://www. programaescolasempartido.org/>. Acesso em: 5 de fev. 2019

. Flagrando o doutrinador. São Paulo, SP, 2004b. Disponível em: $<$ http://escolasempartido.org/flagrando-o-doutrinador>. Acesso em: 15 de abr. 2019.

FRIGOTTO, G. (Org.). Escola "sem” partido: esfinge que ameaça a educação e a sociedade brasileira. Rio de Janeiro, RJ: Universidade Estadual do Rio de Janeiro, 2017.

GIANNOTTI, J. A. Savonarolas oficiais. In: ABRANCHES, S.; ALMEIDA, R.; ALONSO, A. et al. Democracia em risco? 22 ensaios sobre o Brasil hoje. São Paulo, SP: Companhia das Letras, 2019. p. 132-140.

GOFFMAN, E. The presentation of self in everyday life. New York, NY: Archor, 1959.

GUILHERME, A. A.; PICOLI, B. A. Escola sem partido: elementos totalitários em uma democracia moderna: uma reflexão a partir de Arendt. Revista Brasileira de Educação, Rio de Janeiro, v. 23, p. 1-23, 2018. https://doi.org/10.1590/s1413-24782018230042

LEMOS, R. Diante da realidade, seis ficções epistemológicas. In: ABRANCHES, S.; ALMEIDA, R.; ALONSO, A. et al. Democracia em risco? 22 ensaios sobre o Brasil hoje. São Paulo, SP: Companhia das Letras, 2019. p. 158-170.

MACEDO, E. As demandas conservadoras do movimento escola sem partido e a base nacional curricular comum. Educação \& Sociedade, Campinas, v. 38, n. 139, p. 507-24, jun. 2017. https://doi.org/10.1590/es0101-73302017177445 
MOULIN, L. A vida cotidiana dos estudantes na idade média. Lisboa: Livros do Brasil, 1994.

NISBET, R. La tradition sociologique. Paris: Universitaires de France, 1984.

PENNA, F. A. O escola sem partido como chave de leitura do fenômeno educacional. In: FRIGOTTO, G. (Org.). Escola "sem” partido: esfinge que ameaça a educação e a sociedade brasileira. Rio de Janeiro, RJ: Universidade Estadual do Rio de Janeiro, 2017. p. 17-34.

PERNOUD, R. Pour en finir avec le moyen age. Paris: Seuil, 1977.

PASCAL, B. Pensées: texte établi par Louis Lafuma. Paris: Seuil, 1962.

SALDANHA, P. Debate expõe visões 'inconciliáveis' sobre ideologia em sala de aula. Folha de S. Paulo, 4 ago. 2016. Disponível em: <https://www1.folha. uol.com.br/educacao/2016/08/1798773-em-debate-projeto-de-escola-sempartido-e-chamado-de-autoritario.shtml>. Acesso em: 29 jan. 2019.

THIESEN, J.; BIANCHETTI, L. Utopias e distopias na modernidade: educadores em diálogo com Morus, Bacon, Bentham, Huxley e Orwell. Ijuí, RS: Universidade Regional do Noroeste do Estado do Rio Grande do Sul, 2014.

WEBER, M. A ciência como vocação. In: BOTELHO, A. (Org.). Essencial sociologia. São Paulo, SP: Companhia das Letras, 2013. p. 392-431.

\section{Informações dos autores}

Tiago Ribeiro Santos: Doutor em Educação. Professor-visitante no Programa de Pósgraduação em Educação da Universidade Regional de Blumenau. Experiência nas áreas de Sociologia e História da Educação. Contato: tiagoribeiro@furb.br

(iD) http://orcid.org/0000-0002-0941-167X

Gicele Maria Cervi: Doutora em Ciências Sociais. Professora titular do Centro de Ciências da Educação, Artes e Letras e do Programa de Pós-graduação em Educação da Universidade Regional de Blumenau. Líder do Grupo de Pesquisa Políticas da Educação na Contemporaneidade. Contato: giceli.cervi@gmail.com

(iD) https://orcid.org/0000-0003-1667-4643 